УДК 330.3

DOI: https://doi.org/10.37320/2415-3583/9.14

Гурочкіна В.В.

кандидат економічних наук, доцент кафедри економіки підприємства,

Університет державної фіскальної служби України ORCID: https://orcid.org/0000-0001-8869-0189

\title{
КОНВЕРГЕНЦІЯ ЯК БАЗИС ЕМЕРДЖЕНТНОСТІ ЕКОНОМІЧНОЇ СИСТЕМИ
}

У статті висвітлено трактування поняття «конвергенція», проаналізовано гіпотезу конвергениії та особливості ї̈ становлення. Виділено ефекти конвергенції економічних систем, які мають у подальшому прояви емерджентності за рахунок пролонгації конвергенційних властивостей частин иісї системи. Зображено систему конвергенційних та емерджентних властивостей економічної системи. Розглянуто емерджентні прояви системи, шо виникають під час конвергениії нанотехнологій, біотехнологій, інформачійних технологій $і$ технологій, соиіуму, заснованих на когнітивних науках, із тригерами та драйверами. Наведено механізм об'єднань зазначених частин в єдину систему, шьо наділена «новими» якостями - ефектами емерджентності. Запропоновано класифікаційні ознаки: конвергенція емерджентна $\mathrm{NBICS}_{E}$ та конвергенція адитивна $N B I C S_{A}$.

Ключові слова: конвергенція, емерджентність, NBICS, тригери та механізми, частини, система.

Постановка проблеми. Згідно 3 гіпотезою конвергенції, модель розвитку національних економік заснована на адаптації найкращих практик протилежних систем, в яких домінують інерційність та притаманні риси біфуркаційних траєкторій соціально-економічного розвитку. За умов розвитку інтеграційних процесів інформаційних і комунікаційних технологічних платформ виникає в економічних системах ефект конвергенції.

Аналіз останніх досліджень і публікацій. Дослідженням проблем конвергенції і взаємодії в економічних системах та пошуком шляхів підвищення їх результативності займалися зарубіжні й вітчизняні вчені. Розгляд означеної проблеми зумовлює звернення до праць В. Геєця, М. Войнаренка, Л. Абалкіна, Л. Василик, С.В. Сумченко, M. Roco, Bainbridge W. та ін.

Мета статті полягає в узагальненні й характеристиці сучасних теоретичних підходів до трактування поняття «конвергенція» в економічних системах, розробленні авторського підходу й окресленні напрямів і можливостей, які відкриваються завдяки реалізації ендогенних тригерів та механізмів у складному ланцюгу бізнес-процесів, що дає можливість запропонувати авторське бачення розподілу на класифікаційні ознаки 3 урахуванням емерджентних характеристик. Автор має на меті виділити емерджентні прояви системи, що виникають під час конвергенції нанотехнологій, біотехнологій, інформаційних технологій і технологій соціуму, заснованих на когнітивних науках $\left(\mathrm{NBICS}_{\mathrm{E}}\right.$ та $\left.\mathrm{NBICS}_{\mathrm{A}}\right)$.

Виклад основного матеріалу. Конвергенція (3 лат. convergo - «зближаю», convergere - «сходитися до центру», 3 англ. convergence - «сходження в одній точці») означає «злиття», «взаємопроникнення», «взаємний вплив», «наближення», це комунікаційно-інтеграційне явище, що характеризує взаємодію, рух об‘єднання до союзу чи уніфікації розмаїтих частин в єдине ціле, у кінцевому підсумку ефекти діяльності частин у цілому мають зійтися. Результатом конвергенції є ефекти, які виникають на стику галузей, причому відбувається виявлення, ідентифікація та народження «нових» властивостей у слабших частин, які дають змогу «надолужити» розвиток більш сильних частин.

В основі гіпотези конвергенції в економіці лежить ефект «надолуження» біднішою країною (з низькими доходами на душу населення) більш високих темпів економічного зростання, ніж у розвинених (багатих) країнах. У результаті рівень доходу на душу населення всіх економік повинен зійтися. Країни, що розвиваються, мають потенціал до зростання більш високими темпами, ніж розвинені країни, оскільки падіння прибутковості факторів виробництва (зокрема, капіталу) менше, ніж у багатих країнах. Окрім того, більш бідні країни можуть копіювати методи виробництва, технології та інституції, характерні для розвинених країн. Бідні країни, або країни «третього світу», неодноразово робили потужні спроби розвитку, очікуючи в майбутньому на глобальну конвергенцію, проте не змогли іï досягти.

Водночас слід зазначати, що у деяких «азійських тигрів» натомість спостерігалося стійке економічне зростання, незважаючи на значно нижчі за середні показники розвитку країн «третього світу». Отже, питання досягнення конвергенції є складним та багатогранним явищем.

Опис гіпотези конвергенції відображається у концепції Солоу, за якою властивість реальних економічних систем не $є$ чимось принципово новим, а головне - складним для сприйняття, безвідносним щодо положень досліджуваної теоретичної конструкції. Наприклад, національна економіка однієї країни відноситься до категорії зрілих ринкових економік і володіє досить потужною вироб- 
ничо-ресурсною базою, а інша, навпаки, належить до бідної країни з менш розвиненою економікою. Логічно припустити, що сукупна вартість ресурсного забезпечення та основних виробничих фондів у першій національній економіці буде відчутно перевищувати величину за аналогічний показник економіки другої країни:

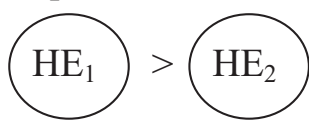

Стає зрозумілим, що за умов дотримання даних обставин для першої національної економіки існує потреба у значному обсязі капіталовкладень для підтримки ресурсного відновлення та виробничого апарату в належному працездатному стані, щоб нівелювати амортизацію, тобто фактично зберігати вже досягнуті розміри агрегованого випуску:

$$
H E_{1}=\sigma \cdot K_{1}>\sigma \cdot K_{2}=H E_{2},
$$

де $\mathrm{K}$ - капіталовкладення.

Згідно 3 даною нерівністю, очевидно, що національна економіка другої країни за інших рівних умов більшою мірою «схильна» до розширення ресурсного та виробничого потенціалу у стабільно меншій його частині завдяки мобілізації валових інвестицій, що акумулюються 3 відшкодувань у процесі економічної діяльності основних фондів.

Повертаючись до моделі Солоу, підкреслимо, що використання терміна «сталий» стосовно стану К не є цілком виправдано й доречно. Головна проблема полягає у тому, що цей стан буде зберігатися лише тоді, коли будуть «сталими» фундаментальні параметри - темпи науково-технічного прогресу i зростання чисельності населення, а також норми заощадження і амортизації. Ці параметри детермінують його величину, тому за значних коливань фундаментальних параметрів посилюється турбулентність національної економіки та зазначеної нерівності. Скажімо, господарська система, яка спочатку перебувала у «стійкому» стані, може зсунутися у бік під впливом активізації надходжень прямих іноземних інвестицій. У такому разі спрацюють ендогенні тригери і механізми, які повернуть іï в «точку відліку».

Слід відзначити, що економічним системам, які досягають ефекту конвергенції, притаманні в подальшій моно (спільній) діяльності ефекти емерджентності за рахунок пролонгації конвергенційних властивостей частин цієї системи. Наявність конвергенційних властивостей створює сприятливе середовище для виникнення «нових» властивостей системи, які не були притаманні частинам раніше.

Ідентифікація сукупності «нових» властивостей у більш слабших частин розцінюється як емерджентний стан системи, який саме окреслює сукупність властивостей системи, якими вона може володіти тільки за умови інтеграції визначених компонентів та їх взаємодії. Емерджентна економічна система, що є динамічною системою в економіко-соціальному середовищі, характеризується цілісністю та взаємодією матеріальних, фінансових, організаційних, соціальних та інформаційних ресурсів. Емерджентна економічна система може бути сформована на різних економічних рівнях - від світової економіки, міжнародних альянсів, національних економік країн і регіонів до окремих промислових або/і торговельних підприємств [2, с. 64].

Ендогенні тригери та механізми застосовуються для забезпечення цілісності даних і реалізації складної логіки бізнес-процесів.

Тригерами (від англ. trigger, flip-flop) уважаємо електронну логічну схему, яка має два стійкі стани, в яких може перебувати економічна система, поки не зміняться відповідним чином сигнали управління. Вихідні індикатори тригера змінюються стрибкоподібно та для них характерні риси біфуркаційних траєкторій розвитку системи.

Сучасний стан розвитку національної економіки свідчить про відсутність впливу рівня розвитку інформаційних технологій на поглинання існуючого виду, вперше в історії відбувається конвергенція - злиття функцій та технологічних можливостей різних сфер та галузей.

Початок XXI ст. характеризується концентрацією зусиль учених в інтеграції наук виходячи 3 положення про єдність природи, сприяючи конвергенції нанотехнологій, біотехнологій, інформаційних технологій і нових технологій, заснованих на когнітивних науках [4, с. 4].

Ілюстрацію конвергенційних та емерджентних властивостей економічної системи відображено на рис. 1.

Указане явище іменується дослідниками також як NBIC-конвергенція (за першими буквами сфер: N - нано; В - біо; I - інфо; C - когно). Термін уведений М. Роко і У. Бейнбріджем, авторами найбільш значної у цьому напрямі на даний момент праці, - звіту Converging Technologies for Improving Human Performance [5, с. 1-2]. Деякі дослідники додають до даної абревіатури $\mathrm{S}$ (соціо), підкреслюючи при цьому соціокультурні виміри комплексу NBIC [3, с. 3].

За об'єднання зазначених частин система стає наділеною «новими» якостями, які не були притаманні частинам цієї системи раніше, тобто можуть досягатися ефекти емерджентності. Тому вважаємо за доцільне виділити в системі класифікаційні ознаки, що поділяють їі на два класи:

- емерджентна NBICS-конвергенція 3 абревіатурою E (емердж), підкреслюючи при цьому емерджентні (неадитивні) властивості комплексу $\mathrm{NBICS}_{\mathrm{E}}$; 


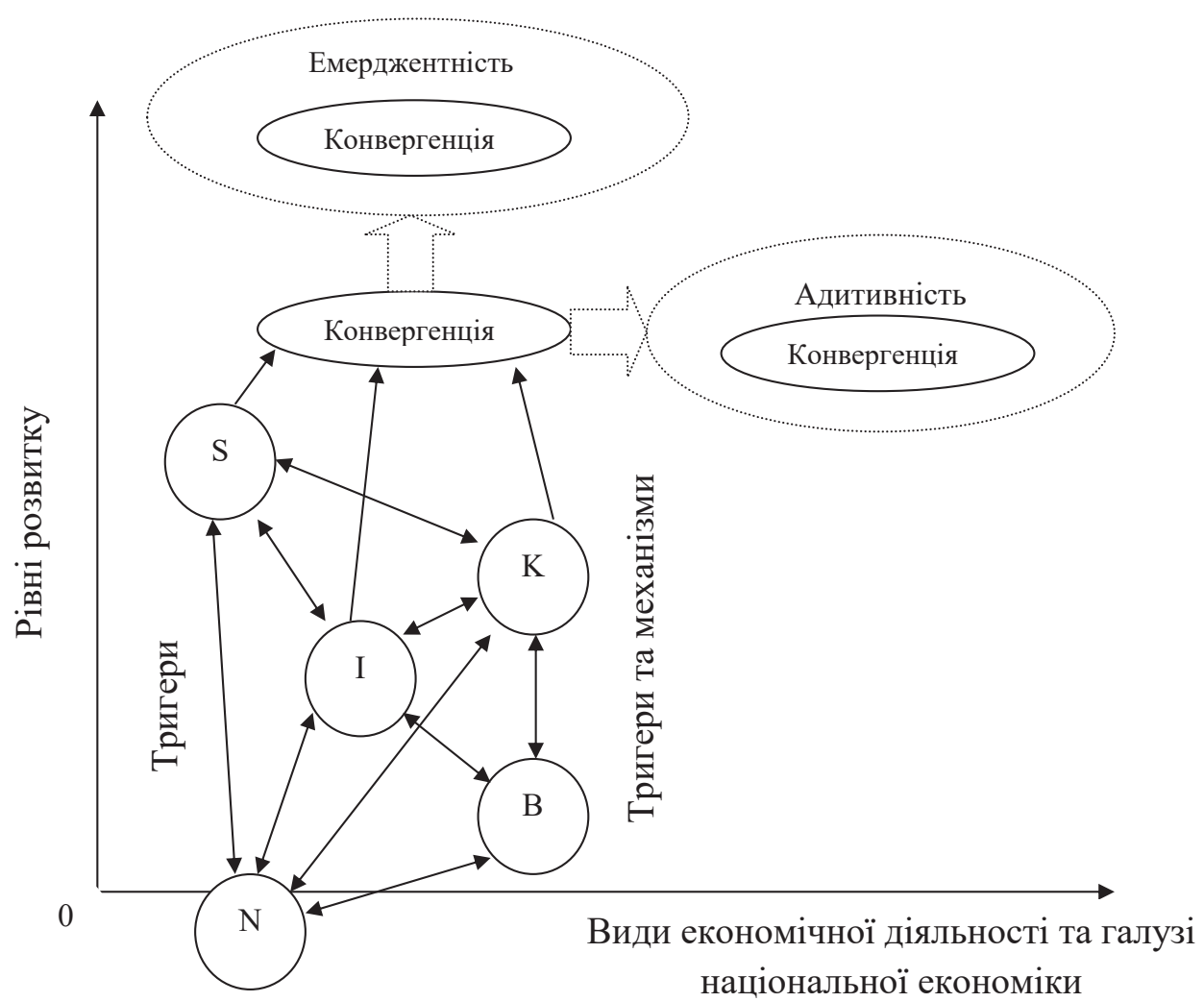

Рисунок 1 - Конвергенція системи 3 проявами емерджентності

Джерело: розробка автора

- адитивна NBICS-конвергенція $з$ абревіатурою А (адитив, від лат. additivus - придатковий, доданий), підкреслюючи при цьому адитивні властивості комплексу $\mathrm{NBICS}_{\text {A }}$.

Висновки. Отже, конвергенція характеризується як комунікаційно-інтеграційне явище, результатом якого $є$ ефекти, що виникають на стику галузей, причому існує можливість виникнення «нових» властивостей у системі. Економічним системам, які досягають ефекту конвергенції, притаманні в подальшій діяльності ефекти емерджентності за рахунок пролонгації конвергенційних властивостей частин цієї системи. Наявність конвергенційних властивостей створює сприятливе середовище для виникнення «нових» властивостей системи, які не були притаманні частинам раніше.

\section{Список використаних джерел:}

1. Василик Л. Конвергенція та крос-медійність: дискурс термінологічної парадигми. 2017. № 1(883). C. 3-9. URL : https://doi.org/10.23939/sjs2017.01.003 (дата звернення: 20.12.2019).

2. Гурочкіна В.В. Емерджентність - феномен складних економічних систем. Вісник Хмельницького національного університету. Економічні науки. 2019. № 6. С. 63-71. DOI : 10.31891/2307-5740-2019-276-6-63-71.

3. Лукьянец В.С. Индустрия научных знаний: NBICS - технологическое расширение окна в будущее. Наука XXI століття, індустрія хай-тек і сучасна освіта. Суми : СумДПУ імені А.С. Макаренка, 2012. С. 3-16.

4. Сумченко С.В. Філософські та світоглядні проблеми практичного застосування NBIC-технологій. Філософія науки: традииї та інновації. 2015. № 1(11). С. 3-11.

5. Roco M., Bainbridge W. Converging Technologies for Improving Human Performance: Nanotechnology, Biotechnology, Information Technology and Cognitive Science. Arlington: National Science Foundation, 2004. 468 p. URL : https://www.wtec. org/ConvergingTechnologies/Report/NBIC_report.pdf (дата звернення: 10.12.2019).

6. Гурочкіна В. В. Інноваційний потенціал підприємства: сутність та система захисту. Економіка: реалії часу. 2015. № 5(21). C. 51-57. URL : http://nbuv.gov.ua/UJRN/econrch_2015_5_10 (дата звернення: 20.12.2019).

7. Гурочкіна В.В., Махортов Ю.О. Стратегічні напрями інклюзивного розвитку України. Проблеми інноваційноінвестиційного розвитку. 2018. № 17. С. 35-44. URL : https://nonproblem.net/wp-content/uploads/2019/12/2019_17_035. pdf (дата звернення: 15.12.2019). 


\title{
References:
}

1. Vasylyk L. (2017). Konverhentsiia ta kros-mediinist: dyskurs terminolohichnoi paradyhmy. [Convergence and crossmedia: the discourse of the terminological paradigm] № 1 (883). p. 3-9. Available at: https://doi.org/10.23939/sjs2017.01.003 [in Ukrainian]. (Accessed: 20.12.2019).

2. Hurochkina V. V. (2019). Emerdzhentnist - fenomen skladnykh ekonomichnykh system. [Emergence is a phenomenon of complex economic systems] Visnyk Khmelnytskoho natsionalnoho universytetu. Ekonomichni nauky. № 6. C. 63-71. Available at: DOI: 10.31891/2307-5740-2019-276-6-63-71. [in Ukrainian].

3. Lukianets B. C. (2012). Yndustryia nauchnыkh znanyi: NBICS- tekhnolohycheskoe rasshyrenye okna v budushchee. [Scientific Knowledge Industry: NBICS- a technological expansion of the window into the future] Nauka XXI stolittia, industriia khai-tek i suchasna osvita. Sumy: SumDPU imeni A. S. Makarenka. p. 3-16. [in Ukrainian].

4. Sumchenko S.V. (2015). Filosofski ta svitohliadni problemy praktychnoho zastosuvannia NBIC-tekhnolohii. [Philosophical and philosophical problems of practical application of NBIC technologies] Filosofiia nauky: tradytsii ta innovatsii. № 1(11). c. 3-11. [in Ukrainian].

5. Roco M., Bainbridge W. (2004). Converging Technologies for Improving Human Performance: Nanotechnology, Biotechnology, Information Technology and Cognitive Science. Arlington: National Science Foundation,. 468 p. Available at: https://www.wtec.org/ConvergingTechnologies/Report/NBIC report.pdf (Accessed: 10.12.2019).

6. Hurochkina V. V. (2015) Innovatsiinyi potentsial pidpryiemstva: sutnist ta systema zakhystu [Innovative potential of the enterprise: essence and system of protection] Ekonomika: realii chasu. Naukovyi zhurnal. no 5 (21). p. 51-57. Available at: https://economics.opu.ua/files/archive/2015/No5/51. (accessed 20 December 2019).

7. Hurochkina V.V., Makhortov Yu.O. (2018) Stratehichni napriamy inkliuzyvnoho rozvytku Ukrainy [Strategic directions of inclusive development of Ukraine] Naukovo-praktychnyi zhurnal «Problemy innovatsiino-investytsiinoho rozvytku». no 17. p. 35-44. Available at: https://nonproblem.net/wp-content/uploads/2018/12/6.pdf (accessed 15 December 2019).

\author{
Hurochkina Viktoriya
}

University of the State Fiscal Service of Ukraine

\section{CONVERGENCE AS THE BASIS OF EMERGENCE OF THE ECONOMIC SYSTEM}

The article deals with the interpretation of the concept of «convergence», analyzes the hypothesis of convergence and peculiarities of its formation. The convergence hypothesis in the economy is based on the effect of "catching up" to a poorer country (with low per capita incomes) at higher rates of economic growth than in developed (rich) countries. As a result, the per capita income level of all economies ultimately converges at one point. Developing countries have the potential to grow at a higher rate than developed countries, since the declining profitability of factors of production (in particular, capital) is smaller than in the rich countries. The effects of convergence of economic systems, which have further manifestations of emergence, due to the prolongation of the convergence properties of parts of this system, are highlighted. The presence of convergence properties creates a favorable environment for the emergence of «new» system properties that were not inherent in parts before. The system of convergent and emergent properties of the economic system is presented. Endogenous triggers and mechanisms used to ensure data integrity and implementation of complex business process logic are characterized. The inequalities of national economies are presented, which reflects the conditions for economies where one is more "prone" to expanding resource and production potential due to the mobilization of gross investments accumulated from compensation in the course of economic activity of fixed assets. The author states that emergence manifestations of the system occur in the convergence of nanotechnology, biotechnology, information technology, and technologies, society based on the cognitive sciences. The author's vision of the mechanism of combining these parts is given, when the system becomes endowed with «new» qualities that were not inherent in the parts of this system before and the emergence effects can be achieved. On the basis of this study, the classification features are distinguished in the system, which is proposed to be divided into two classes. The proposed emergence convergence $N B I C S_{E}$ and additive convergence $N B I C S_{A}$.

Key words: convergence, emergence, NBICS, triggers and mechanisms, parts, system.

JEL Classification: Q49, C69, M11. 